\title{
The Collaboration Management and Employee Views of Work and Skills in Services for Children and Families in Finnish Municipalities
}

\section{The Collaboration Management and Employee Views of Work and Skills}

I Outi Kanste'

PhD, Senior Researcher, National Institute for Health and Welfare, Finland

I Nina Halme

PhD, Senior Researcher, National Institute for Health and Welfare, Finland

\section{Marja-Leena Perälä}

PhD, Research Professor, National Institute for Health and Welfare, Finland

\begin{abstract}
The study explored how collaboration management is connected with employee views of work and skills in the health care, social welfare, and education sectors that provide services for children and families in municipalities. Collaboration management in children and family services involves increasing awareness of services, organizing agreed collaboration practices, overcoming barriers to collaboration, managing difficult relationships with coworkers, and contributing purposively to the functionality of collaboration.

Data were gathered using a postal survey. The sample consisted of 457 employees working in the health care, social welfare, and educational settings in Finnish municipalities. Overall, the results suggested that collaboration management is related to employees' positive views of work and versatile skills. Good awareness of services, well agreed-upon collaboration practices, and wellfunctioning collaboration were associated with employees' influence over their own work, social support being received from managers, a perception of leadership justice, employee collaboration skills, and employee retention. On the other hand, barriers to collaboration seemed to reduce employees' influence over their own work, social support, perceptions of leadership justice, collaboration skills, and employee retention.

The findings indicate the need for effective collaboration management in multidisciplinary environments between the health care, social welfare, and education sectors that provide services for children and families to achieve employees' positive views of work and versatile skills.
\end{abstract}

\section{KEY WORDS}

Child / collaboration / education / health and social services / management

DOI

10.19154/njwls.v6il.4910

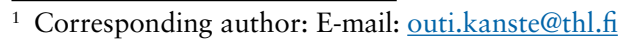




\section{Introduction}

he strengthening of collaboration and the development of collaboration structures between stakeholders providing services for children and families has been a key issue in health, social, and education policy in many Western countries (Bachmann et al., 2009; Widmark et al., 2011; Wolfe et al., 2013). The fragmentation and differentiation of the service system together with insufficient collaboration can reduce access for children and families to services, as well as influencing some to drop out of the service system. These factors present challenges for service providers to collaborate in meeting the needs of children and families in an appropriate, timely, and customer-oriented way (Willumsen et al., 2012; Wolfe et al., 2013). Flexible collaboration between different service providers also enables a more effective allocation of resources, resulting in financial savings.

\section{The State of the Art of Collaboration Management and Its Benefits}

The literature related to the concept of collaboration is diverse (Ødegård \& Strype, 2009; Willumsen, 2008; Willumsen et al., 2012). Chris Huxham and Siv Vangen (2005) use the term collaboration to refer to any situation in which people are working across organizational boundaries toward some positive end. Interprofessional collaboration can be perceived as internal collaboration between professionals from the same organization and external collaboration as between professionals from different organizations or services (Ødegård \& Strype, 2009). Elisabeth Willumsen (2008) has stated that interprofessional collaboration can be considered as taking place between professionals and between professionals and service users on an interpersonal level, as well as between organizations or services on an interorganizational level.

In this study, collaboration in services for children and families is viewed from the conceptual framework of integration in public health. With the increasing functional and structural differentiation of organizations involved in the pursuit of services for children and families, there is a growing need for interorganizational integration. Concerning collaboration, integration is accomplished through voluntary agreements and mutual adjustments between the organizations involved. This form of integration is based on a willingness to work together, and it may be implemented through intensive contacts and communications (Axelsson \& Axelsson, 2006).

The management of interorganizational collaboration includes facilitation of contracts, conflict management, trust management, and facilitation of work. Managing collaboration seems to be difficult. Problems can stem from the different professional and organizational cultures and interests (Axelsson \& Axelsson, 2006), incomplete understanding of roles and responsibilities, lack of trust (Atkinson et al., 2007; Widmark et al., 2011), insufficient knowledge of each other's activities or available services, and inadequate feedback (Widmark et al., 2011). Moreover, collaboration can be further complicated by conflicting and defensive interprofessional relationships, communication problems, unrealistic expectations, and lack of resources (Atkinson et al., 2007; Widmark et al., 2011). Structural factors are related to the existence of separate administrative boundaries, different laws and regulations, budgets and information systems, and the absence of structures supporting collaboration and agreed collaboration practices.

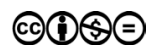


Collaboration between service providers in health care, social care, and education has been shown to be beneficial for service users, children and their families and professionals, as well as organizations (Atkinson et al., 2007; Oliver et al., 2010; Willumsen et al., 2012). The effects on professionals of managed collaboration have been generally studied through integrated and multiagency working and multidisciplinary teams. The most commonly identified benefits of integrated and multiagency working for professionals are improved services and joint problem-solving, the ability to take a holistic approach, and increased trust and communication (Atkinson et al., 2007; Moran et al., 2007). Evidence indicates that multiagency working is generally well received by professionals and appears to produce positive impacts in relationships with colleagues, and in relation to professionals' personal and career development and professional practice (Oliver et al., 2010). Multiagency working can lead to greater knowledge and understanding of the roles of colleagues from other professions, as well as of cross-disciplinary issues (Abbott et al., 2005; Anning, 2005; Atkinson et al., 2007; Moran et al., 2007). Multiagency working enhances awareness of the needs of children and families (Atkinson et al., 2007) and the range of services available to children and families across the public and voluntary sectors (Worrall-Davies \& Cottrell, 2009).

Moreover, multiagency working offers professionals the opportunity to develop a new and expanded work role, usually involving a range of new tasks. It has shown a positive impact on professional identities, as a result of increased accountability and professional confidence, as well as providing opportunities for creativity and autonomy (Abbott et al., 2005; Atkinson et al., 2007, Moran et al., 2007). The acquisition of a wider range of skills in the workplace has also been identified (Worrall-Davies \& Cottrell, 2009) and improvements in access to information, information sharing, confidence, communication, and interaction between professionals (Abbott et al., 2005; Atkinson et al., 2007; Moran et al., 2007). Multiagency working is related to professionals' enjoyment in everyday working lives (Abbott et al., 2005) and perceptions of rewarding and stimulating work (Atkinson et al., 2007). Professionals have also reported reduced levels of stress and increased job satisfaction (Atkinson et al., 2007).

On the other hand, there is partly conflicting evidence on some negative impacts of multiagency working on professionals, which largely centers on increased workloads, uncertainty or confusion regarding professional identities or status, and the questioning of individual roles (Abbott et al., 2005; Atkinson et al., 2007; Oliver et al., 2010). There is also evidence of duplication between different multiagency teams and increased demands and pressure on professionals (Abbott et al., 2005; Atkinson et al., 2007).

The most successful forms of interorganizational collaboration in public health seem to be multidisciplinary teams (Axelsson \& Axelsson, 2006). Team structure and job design contribute to employee well-being, greater satisfaction, and lower stress (So et al., 2011). Membership in well-structured teams that show clarity in team and individual goals, that meet regularly, and that recognize the diverse skills of their members is known to reduce levels of employee stress and strain by increasing job satisfaction and preventing the intention to leave the job (Buttigieg et al., 2011). Improving the team atmosphere, as indicated by clear and shared goals, participation, task orientation and support for innovation, may reduce turnover and intentions to leave among hospital employees (Kivimäki et al., 2007).

Building on these findings, we propose that collaboration management in children and family services may result in employees' positive views of work and versatile skills. 
In light of the conceptual framework of integration (Axelsson \& Axelsson, 2006) and in line with previous knowledge (Axelsson \& Axelsson, 2006; Huxham \& Vangen, 2005), collaboration management involves increasing awareness of services, organizing agreed collaboration practices, overcoming barriers to collaboration, managing difficult relationships, and contributing purposively to the functionality of collaboration.

This study is a valuable contribution to the research literature, because research evidence of collaboration management and its usefulness in multidisciplinary environments between health care, social welfare, and education sectors are limited. Taking into account the state of art, our contribution to the field concerning the research theme is that collaboration management in services for children and families is viewed from different perspectives. Good awareness of services that other actors are providing to children and families is a key prerequisite for collaboration. Agreed collaboration practices involve written agreements on shared goals, harmonization of working methods, commitment to common goals, formation of joint services, information flows, and written agreements on joint monitoring and evaluation (Halme et al., 2014; Perälä et al., 2011). Collaboration between different service providers may be entangled with many barriers concerning work cultures, management, work environment, and resources, among others (Atkinson, 2007; Axelsson \& Axelsson, 2006; Widmark et al., 2011). Difficult relationships with coworkers, for example, noncompliance with the agreed procedures or inappropriate behavior, can complicate collaboration in multidisciplinary teams. Well-functioning collaboration between different service providers is needed in fragmented children and family services (Halme et al., 2014; Perälä et al., 2011).

Our contribution to the field concerning the research theme is also that employee views of work and skills are examined through the factors, which have been paid only little attention in previous studies, for example, perceptions of leadership justice. Collaboration management may foster employee positive views of work, such as influence over own work (e.g., work tasks, working methods, and division of duties) as well as experience of empowering and skills-oriented social support received from manager. Collaboration management may also lead to leadership being perceived fair; the manager can be trusted and he or she respects employees and listens to their opinions equally. In addition, collaboration management can promote employees' collaboration skills and support staff to stay in their jobs and to prevent turnover (Halme et al., 2014; Perälä et al., 2011). The conceptual framework of this study is presented in Figure 1. Integration and collaboration in services of children and families are strongly highlighted.

\section{Study purpose}

The purpose of the study was to explore how collaboration management is connected with employee views of work and skills in the health care, social welfare, and education sectors that provide services for children and families in Finnish municipalities.

The research question was as follows: How does collaboration management (employee awareness of services, agreed collaboration practices, barriers to collaboration, difficult relationships with coworkers, and functionality of collaboration) relate to the employee views of work and skills (individual's influence over their own work, social support being received from managers, perceptions of leadership justice, employee collaboration skills, and retention)?

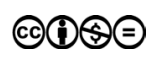


Figure I: Conceptual framework.

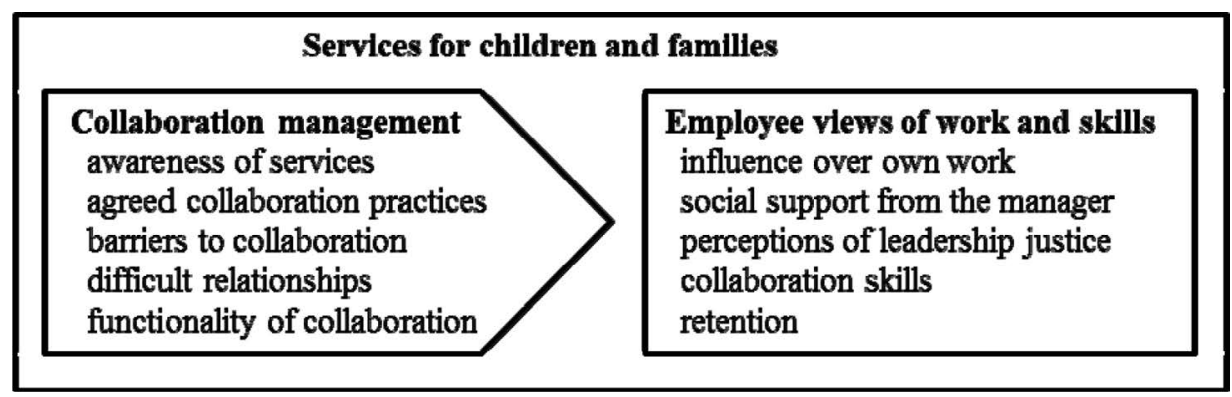

\section{Methods}

\section{Study design and research setting}

The study was carried out with a cross-sectional survey design. Data were gathered using a postal survey in 2009 sent to employees working in the health care, social welfare, and educational settings providing services for children and families in Finnish municipalities. Taking into account the state of art, our contribution to the field concerning the data is that it was gathered from employees working in multidisciplinary environments and different sectors providing services for children and families.

This study was conducted in Finnish municipalities. In Finland, municipalities have extensive duties and obligations to provide health, social and other welfare, education and cultural services, as well as to provide a physical infrastructure at the local level. They have the right to levy taxes to cover the costs of providing services. The major part of the services is run and funded publicly by the municipalities, who provide services by themselves, jointly with other municipalities, or purchase services from other service providers such as voluntary and private organizations (European Commission, 2010; OECD, 2014; Teperi et al., 2009; Vuorenkoski, 2008). The Finnish public service system is strongly decentralized compared to other OECD countries, while national steering is rather weak (OECD, 2014; Teperi et al., 2009). Since each municipality determines its own scope of coverage within general limits set by national legislation and the extent of collaboration across municipalities is limited, a fair amount of variation exists regionally in public services (Teperi et al., 2009; Vuorenkoski, 2008). The municipal health care system has separate organizational structures in place for primary and secondary services, which has clearly hindered collaboration between these levels (Vuorenkoski, 2008). The schools also have the right to provide educational services according to their own administrative arrangements, as long as the basic functions, determined by law, are carried out (European Commission, 2010).

In the last 15 years, several local reforms have been enacted to enhance collaboration between primary and secondary health care and social welfare services by integrating organizations (Vuorenkoski, 2008). A number of laws, regulations, and recommendations at the national level concerning health care, social welfare, and education services guide collaboration between service providers and employees in municipalities. Children and family services in Finnish municipalities are organized in slightly different ways and 
are provided through a number of service providers in the public, private, and voluntary sectors (Halme et al., 2014; Perälä et al., 2011). The ongoing social welfare and health care service structure reforms and local government reforms in Finland are aimed at modifying service structures for children and families in such a way as to ensure services form a single entity and to foster collaboration (Teperi et al., 2009; Vuorenkoski, 2008).

\section{Study population}

The study population was formed from operational units providing services for children and families in municipalities in the Finnish mainland $(\mathrm{n}=332)$, with five types of units included: (1) maternity and child welfare, (2) school health care, (3) day care, (4) preschool, and (5) basic education units. In these municipalities a random sample of the above-mentioned operational units was selected for the study. A total of 1,220 questionnaires were sent to the participating units. After one survey reminder, 457 respondents returned fully completed questionnaires, giving a response rate of $37 \%$.

The appropriate sample size was calculated with a power analysis. A significance level of $95 \%(\alpha=0.05)$ and a statistical power of $80 \%$ were used (Cohen, 1988). The analysis showed that the data used were adequate in relation to the methods of analysis.

The questionnaires were answered anonymously and municipality-specific results were not published. Ethical approval (\$43/2009) was obtained from the Ethical Review Board of the National Institute of Health and Welfare in Finland.

\section{Participants}

A total of 457 employees participated in the study (Tab. 1). Almost half were older than 50 years and had more than 14 years of work experience in their current position. The vast majority (93\%) were permanent employees. About a third worked in health care, a third in education services, a quarter in combined social welfare and health care services, and a tenth in social welfare services.

A little more than a third of participants worked in frontline managerial positions. Frontline managers were examined as part of the group of employees because they are responsible for the daily management of line employees who offer the services and most employees interact with them on a daily basis. Frontline managers do not usually set goals for the organization at a strategic level or direct the organization in achieving them. However, many of them work themselves directly with day-to-day activities, such as customer or patient work, in addition to management responsibilities. They are working under the middle or top-level managers.

\section{Measures}

The questionnaire was developed for the purposes of the study and was based on theory, previous research, and multidisciplinary knowledge of services for children and families (Halme et al., 2014; Perälä et al., 2011). Questionnaire included background factors (Tab. 1). The main study variables are described in Table 2. 
Table I The demographic characteristic of the participants $(n=457)$

\begin{tabular}{|c|c|c|}
\hline Characteristic & $\%$ & $n$ \\
\hline \multicolumn{3}{|l|}{ Age } \\
\hline less than 40 years & 18 & 80 \\
\hline $40-50$ years & 36 & 160 \\
\hline more than 50 years & 46 & 203 \\
\hline \multicolumn{3}{|l|}{ Educational level } \\
\hline higher university level or more & 16 & 72 \\
\hline lower university level & 36 & 161 \\
\hline vocational school or less & 48 & 212 \\
\hline \multicolumn{3}{|l|}{ Work experience in current position } \\
\hline less than 5 years & 26 & 117 \\
\hline $5-14$ years & 33 & 149 \\
\hline more than 14 years & 41 & 181 \\
\hline \multicolumn{3}{|l|}{ Working in frontline managerial position } \\
\hline yes & 37 & 165 \\
\hline no & 63 & 283 \\
\hline \multicolumn{3}{|l|}{ Sector } \\
\hline combined social welfare and health care & 23 & 101 \\
\hline health care & 32 & 146 \\
\hline social welfare services & 12 & 53 \\
\hline education services & 33 & 149 \\
\hline \multicolumn{3}{|l|}{ Number of employees in work unit } \\
\hline under 10 & 37 & 162 \\
\hline $10-50$ & 52 & 226 \\
\hline more than 50 & 11 & 47 \\
\hline \multicolumn{3}{|l|}{ Number of population in the municipality } \\
\hline under 4,000 inhabitants & 14 & 61 \\
\hline $4,000-15,000$ inhabitants & 57 & 258 \\
\hline more than 15,000 inhabitants & 29 & 131 \\
\hline
\end{tabular}


Table II Main study variables, number of items and, Cronbach's alphas

\begin{tabular}{|c|c|c|c|c|}
\hline Study variables & Mean & SD & Items & Alpha \\
\hline Awareness of services & 3.62 & 0.61 & 14 & 0.88 \\
\hline Agreed collaboration practices & 3.16 & 0.69 & 30 & 0.95 \\
\hline Agreement of shared goals & 3.10 & 0.90 & 5 & 0.81 \\
\hline Harmonization of working methods & 3.10 & 0.90 & 5 & 0.82 \\
\hline Commitment to common goals & 3.38 & 0.78 & 5 & 0.81 \\
\hline Formation of joint services & 3.36 & 0.76 & 5 & 0.81 \\
\hline Flow of information & 3.10 & 0.77 & 5 & 0.80 \\
\hline Agreement of monitoring and evaluation & 2.93 & 0.96 & 5 & 0.88 \\
\hline Barriers to collaboration & 2.74 & 0.75 & 19 & 0.94 \\
\hline Work culture and attitudes & 2.40 & 0.82 & 6 & 0.87 \\
\hline Management practices & 2.68 & 0.88 & 7 & 0.90 \\
\hline Environmental factors & 2.79 & 0.91 & 3 & 0.63 \\
\hline Lack of resources & 3.10 & 0.96 & 3 & 0.74 \\
\hline Difficult relationships with coworkers & 1.38 & 0.31 & 7 & 0.74 \\
\hline Functionality of collaboration & 3.98 & 0.59 & 32 & 0.95 \\
\hline Employees' influence over their own work & 3.89 & 0.66 & 6 & 0.79 \\
\hline Empowering support behavior & 3.73 & 0.59 & 5 & 0.82 \\
\hline Skills-oriented support activities & 3.37 & 0.69 & 7 & 0.80 \\
\hline Perceptions of leadership justice & 3.97 & 0.85 & 7 & 0.93 \\
\hline Employees' collaboration skills & 4.25 & 0.54 & 2 & 0.74 \\
\hline Employees' retention & 4.09 & 0.90 & 1 & - \\
\hline
\end{tabular}

Collaboration management was investigated by way of employees' awareness of services, agreed collaboration practices, barriers to collaboration, difficult relationships with coworkers, and the functionality of collaboration. Awareness of services for children and families was measured with 14 items using a five-point scale (very poor to very good). Information on the agreed collaboration practices between sectors and municipalities and with third- and private-sector actors providing services for children and families was elicited using a 30 -item measure consisting of six subscales. These subscales evaluated written agreements on shared goals, harmonization of working methods, commitment to common goals, formation of joint services, information flows, and written agreements on joint monitoring and evaluation. A five-point scale (strongly disagree to strongly agree) was used (Halme et al., 2014; Perälä et al., 2011). 
Barriers to collaboration were measured using a 19-item measure with a five-point scale (very little to very much). Items were formed into four subscales: work culture and attitudes, management practices, environmental factors, and lack of resources. Difficult relationships with coworkers within the previous 12 months were measured with seven items on a three-point scale (not at all to often). Functionality of collaboration within the previous 12 months with primary health care, social welfare, education, and special health care services, as well as in mental health and substance abuse services provided to children and families was measured with 32 items on a five-point scale (very poor to very good) (Halme et al., 2014; Perälä et al., 2011) (Tab. 2).

The employee views of work and skills investigated were individual's influence over their own work, social support, leadership justice, and employees' collaboration skills and retention. Employees' influence over their own work was measured with a modification of the Job Content Questionnaire (Karasek et al., 1998). The measure included six items using a five-point response scale (very poor to very good). Perceptions of social support from managers were measured with the 12-item Supervisory Support Measure (Räikkönen et al., 2007) using a five-point scale (poor to excellent). Items were formed into two subscales: empowering support behavior and skills-oriented support activities. Perceptions of leadership justice were evaluated with seven items on a five-point scale (strongly disagree to strongly agree). Employees' collaboration skills were measured with two items and retention with one item, using a five-point response scale (very poor to very good) (Halme et al., 2014).

\section{Data analysis}

Descriptive statistics were used to characterize the participants. To investigate the relationships between the study variables we used a Chi-square test, the Pearson productmoment correlation coefficient, the independent samples t-test, and one-way analysis of variance. Standard multiple linear regression analysis was performed using employee views of work and skills as the dependent variables and collaboration management and background factors as the independent variables to explore how these factors as a group explained the variance in employee views of work and skills (Montgomery et al., 2012). Working in a managerial position was the only statistically significant background factor in the analysis; hence it was chosen for the final models. Statistical significance was set with a p-value of $<0.05$. Cronbach's $\alpha$ was used in the reliability analysis. The internal consistencies of the subscales were satisfactory (Nunnally \& Bernstein, 1994), since the alphas ranged between 0.63 and 0.95 (Tab. 2).

\section{Results}

\section{Collaboration management}

Two-thirds (62\%) of employees agreed to some extent that there were agreed collaboration practices between different parties serving children and families, though $13 \%$ considered awareness of services to be poor. More than one-third (38\%) have encountered many barriers to collaboration and almost a third $(30 \%)$ at least sometimes difficult 
relationships with coworkers. About half (53\%) considered the functionality of collaboration to be rather or very good with different parties.

\section{Employees' influence over their own work}

Three-quarters $(73 \%)$ of employees stated that their influence over their own work was good or very good. Highly educated employees considered the influence over their own work to be good more often than less educated employees $(F(2)=3.70, p=0.026)$. Employees working in managerial positions more often thought they had an influence over their own work than those employees not working as managers $(\mathrm{t}(441)=-2.15$, $\mathrm{p}=0.032$ ). Employees' influence over their own work was rated higher by those working in education services compared to health care and social welfare services $(F(3)=$ $4.92, \mathrm{p}=0.002)$. The proportion of employees with at least a higher university degree was greater in education services than in other sectors $\left(\chi^{2}(6)=125.4, p<0.001\right)$.

Awareness of services, agreed collaboration practices, barriers to collaboration, and functionality of collaboration were slightly related to employees' influence over their own work (Tab. 3).

Table III Correlations of the main study variables $(n=457)$

\begin{tabular}{|c|c|c|c|c|c|c|c|c|c|c|c|}
\hline Main study variables & । & 2 & 3 & 4 & 5 & 6 & 7 & 8 & 9 & 10 & | \\
\hline I. Awareness of services & । & & & & & & & & & & \\
\hline $\begin{array}{l}\text { 2. Agreed collaboration } \\
\text { practices }\end{array}$ & 0.16 & । & & & & & & & & & \\
\hline $\begin{array}{l}\text { 3. Barriers to } \\
\text { collaboration }\end{array}$ & -0.23 & -0.26 & । & & & & & & & & \\
\hline $\begin{array}{l}\text { 4. Difficult relationships } \\
\text { with coworkers }\end{array}$ & -0.11 & -0.06 & 0.30 & । & & & & & & & \\
\hline $\begin{array}{l}\text { 5. Functionality of } \\
\text { collaboration }\end{array}$ & 0.33 & 0.26 & -0.36 & -0.06 & । & & & & & & \\
\hline $\begin{array}{l}\text { 6. Employees' influence } \\
\text { over their own work }\end{array}$ & 0.14 & 0.19 & -0.21 & -0.05 & 0.19 & I & & & & & \\
\hline $\begin{array}{l}\text { 7. Empowering support } \\
\text { behavior }\end{array}$ & 0.20 & 0.25 & -0.30 & -0.16 & 0.19 & 0.53 & 1 & & & & \\
\hline $\begin{array}{l}\text { 8. Skills-oriented } \\
\text { support activities }\end{array}$ & 0.23 & 0.19 & -0.18 & -0.04 & 0.17 & 0.34 & 0.59 & I & & & \\
\hline $\begin{array}{l}\text { 9. Perceptions of } \\
\text { leadership justice }\end{array}$ & 0.18 & 0.26 & -0.26 & -0.20 & 0.19 & 0.21 & 0.43 & 0.41 & I & & \\
\hline $\begin{array}{l}\text { 10. Employees' } \\
\text { collaboration skills }\end{array}$ & 0.33 & 0.19 & -0.23 & -0.32 & 0.17 & 0.24 & 0.33 & 0.20 & 0.16 & I & \\
\hline I।. Employees' retention & 0.19 & 0.04 & -0.20 & -0.28 & 0.17 & 0.18 & 0.20 & 0.12 & 0.10 & 0.37 & । \\
\hline
\end{tabular}


In the one-way analysis of variance, employees' influence over their own work was rated higher when agreed collaboration practices were rated as operating very well compared to when agreed collaboration practices were rated to operate poorly. However, employees' influence over their own work was rated lower when there were seen to be many barriers to collaboration compared to few barriers. Moreover, only harmonization of working methods and barriers concerning work cultures and attitudes was not statistically significantly related to employees' influence over their own work (Tab. 4).

For employees' influence over their own work, $8 \%$ of the total variance was explained by agreed collaboration practices, barriers to collaboration, functionality of collaboration, and working in a managerial position (Tab. 5).

\section{Empowering support behavior}

More than two-thirds $(68 \%)$ of employees assessed that empowering support received from managers was good or excellent. Highly educated employees more often experienced empowering support behavior $(\mathrm{F}(2)=6.47, \mathrm{p}=0.002)$ than less educated employees. Employees working in managerial positions more often thought that empowering support behavior occurred than those employees not working as managers $(\mathrm{t}(391)=$ $-7.14, \mathrm{p}<0.001)$. Empowering support behavior appeared less frequently in health care than in social welfare and education services $(\mathrm{F}(3)=13.91, \mathrm{p}<0.001)$.

All the measured collaboration management factors were to some extent related to empowering support behavior (Tab. 3). Empowering support behavior appeared more often when awareness of services was good, when agreed collaboration practices were rated to operate very well, or when functionality of collaboration was rated as very good than if awareness was poor, if agreed collaboration practices were rated to operate poorly, or if functionality of collaboration was rated as poor. Empowering support behavior took place less frequently when there were many barriers to collaboration or when work relationships were more often difficult, as opposed to when barriers were few or relationships were sometimes or never difficult. Moreover, only harmonization of working methods and agreement on monitoring and evaluation were not statistically significantly related to empowering support behavior (Tab. 4).

For empowering support behavior, $23 \%$ of the total variance was explained by awareness of services, agreed collaboration practices, barriers to collaboration, functionality of collaboration, and working in a managerial position (Tab. 5).

\section{Skills-oriented support activities}

A little less than half $(46 \%)$ of employees rated the skills-oriented support received from managers to be good or excellent. Highly educated employees more often reported skills-oriented support activities $(\mathrm{F}(2)=3.45, \mathrm{p}=0.033)$ compared to less educated employees. Employees working in a managerial position thought that these activities appeared more often than those employees not working as managers $(\mathrm{t}(375)=-6.98$, $\mathrm{p}<0.001)$. Skills-oriented support activities appeared less frequently in health care than within social welfare and education services settings $(F(3)=3.73, p=0.011)$. They also appeared less frequently in work units with less than 10 employees than in larger ones 


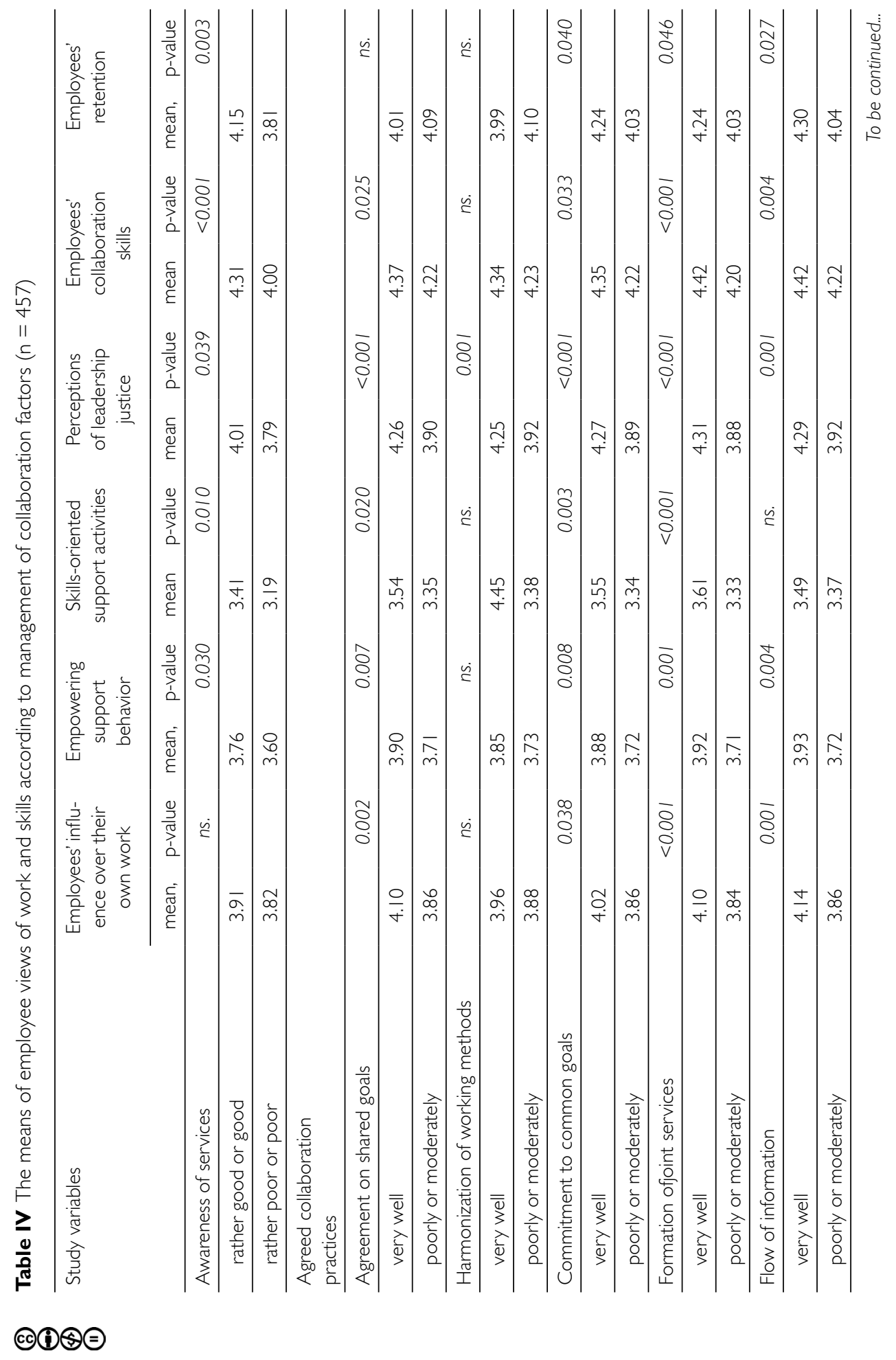




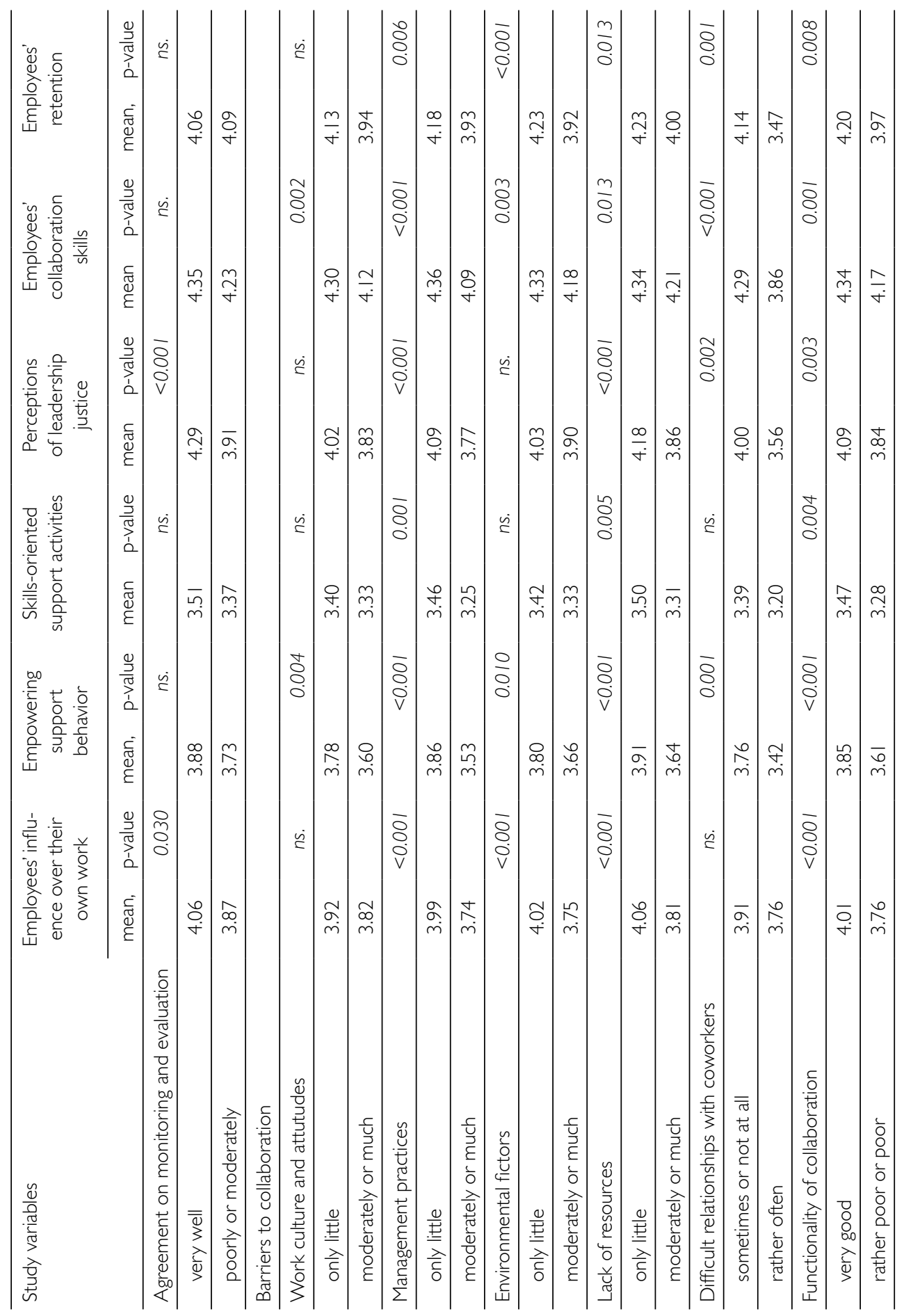




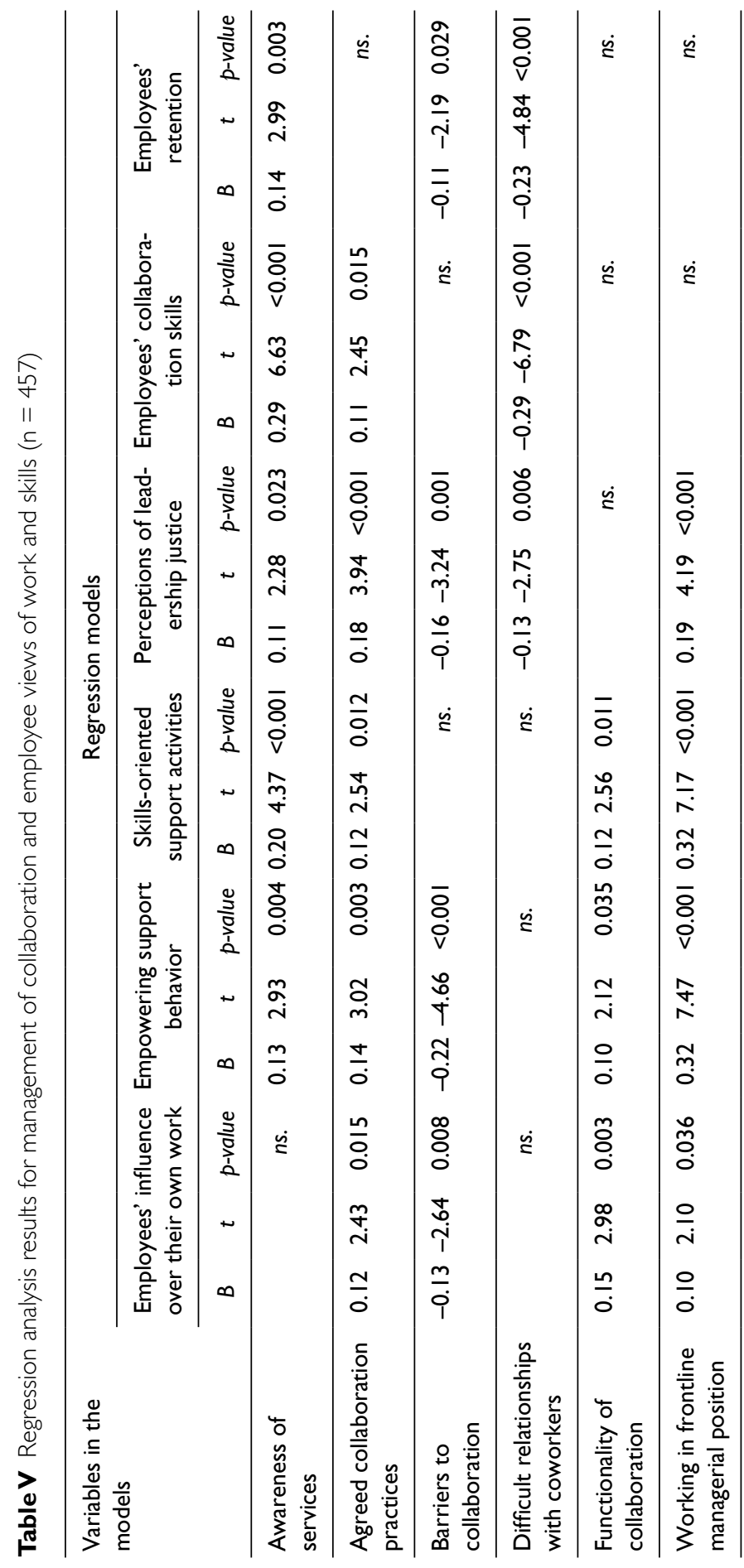


$(\mathrm{F}(2)=6.07, \mathrm{p}=0.003)$ and in municipalities with 15,000 inhabitants or less than in larger ones $(\mathrm{F}(2)=4.57, \mathrm{p}=0.011)$.

Skills-oriented support activities were slightly associated with awareness of services, agreed collaboration practices, barriers to collaboration, and functionality of collaboration (Tab. 3). Skills-oriented support activities appeared more often when awareness was good, when agreed collaboration practices were rated to operate very well, or when functionality of collaboration was rated as very good than if awareness was poor, if agreed collaboration practices were rated to operate poorly, or if functionality of collaboration was rated as poor. However, skills-oriented support activities appeared less frequently when barriers to collaboration were common as compared to when they were not. Moreover, skills-oriented support activities were not significantly related to the harmonization of working methods, flow of information, agreement on monitoring and evaluation, environmental factors, and finally to barriers concerning work cultures and attitudes (Tab. 4).

For skills-oriented support activities, $18 \%$ of the total variance was explained by awareness of services, agreed collaboration practices, functionality of collaboration, and working in a managerial position (Tab. 5).

\section{Perceptions of leadership justice}

Three-quarters (74\%) of employees fully or partially agreed that leadership justice was implemented well. Employees working in a managerial position thought that leadership justice was implemented more frequently than employees not working as managers $(t(386)=-3.87, p<0.001)$. Leadership justice was more frequently perceived as having been achieved in health care than in social welfare and education services $(F(3)=3.67$, $\mathrm{p}=0.012$ ).

All the measured collaboration management factors were to some extent related to perceptions of leadership justice (Tab. 3). Leadership justice was more frequently seen to be achieved when awareness of services was good, when agreed collaboration practices were rated to operate very well, or when functionality of collaboration was rated as very good compared to when awareness was poor, when agreed collaboration practices were rated to operate poorly, or when the functionality of collaboration was rated as poor. Leadership justice was realized less frequently when barriers to collaboration appeared often or difficult relationships appeared rather often, as opposed to when barriers appeared only rarely or when relationships were sometimes or not at all difficult. On the other hand, barriers concerning work cultures and attitudes and environmental factors were not statistically significantly related to perceptions of leadership justice (Tab. 4).

For perceptions of leadership justice, $15 \%$ of the total variance was explained by awareness of services, agreed collaboration practices, barriers to collaboration, difficult relationships, and working in a managerial position (Tab. 5).

\section{Employees' collaboration skills}

Almost half $(43 \%)$ of the employees stated that collaboration skills were very good. All the measured collaboration management factors were slightly related to employees' 
collaboration skills (Tab. 3). Skills were better when awareness of services was good, when agreed collaboration practices were rated to operate very well, or when functionality of collaboration was rated as very good than when awareness was poor, when agreed collaboration practices were rated to operate poorly, or when functionality of collaboration was rated as poor. Collaboration skills were poorer when barriers to collaboration appeared often or when relationships were rather often seen as difficult compared to when barriers did not appear often or when relationships were sometimes or not at all seen as difficult. Moreover, only harmonization of working methods and agreement on monitoring and evaluation were not statistically significantly related to collaboration skills (Tab. 4).

For employees' collaboration skills, $21 \%$ of the total variance was explained by awareness of services, agreed collaboration practices, and difficult relationships (Tab. 5).

\section{Employees' retention}

More than one third (37\%) of employees stated that employee retention was very good. The number of employees in the work unit was related to retention. Retention was better in work units with less than 10 employees than in larger ones $(F(2)=6.33, p=0.002)$.

Awareness of services, barriers to collaboration, difficult relationships, and functionality of collaboration were slightly related to retention (Tab. 3). The retention was better when awareness of services was good or when functionality of collaboration was rated as very good than when awareness was poor or when functionality of collaboration was rated as poor. However, employees' retention was weaker when barriers to collaboration appeared to be many or when relationships were rather often seen as difficult, as opposed to when barriers appeared only rarely, or relationships were sometimes or not at all seen as difficult. On the other hand, barriers concerning work cultures and attitudes were not statistically significantly related to retention, whereas commitment to common goals, formation of joint services, and flow of information were positively related to it (Tab. 4).

For employee retention, $11 \%$ of the total variance was explained by awareness of services, barriers to collaboration, and difficult relationships (Tab. 5).

\section{Discussion}

In light of the conceptual framework of integration (Axelsson \& Axelsson, 2006) and in line with previous knowledge (Axelsson \& Axelsson, 2006; Huxham \& Vangen, 2005), collaboration management in children and family services involves increasing awareness of services, organizing agreed collaboration practices, overcoming barriers to collaboration, managing difficult relationships, and contributing purposively to the functionality of collaboration.

Results showed that well agreed-upon collaboration practices between different municipal sectors and municipalities and with third- and private-sector actors providing services for children and families as well as well-functioning collaboration with them seem to increase the employees' influence over their own work, whereas barriers to collaboration appear to reduce it. According to previous evidence, collaboration 
management has a positive impact on professional identities, bringing increased accountability, professional confidence, and opportunities for creativity and autonomy (Abbott et al., 2005; Atkinson et al., 2007; Moran et al., 2007). On the other hand, it can cause uncertainty or confusion regarding professional identities and a questioning of individual roles (Abbott et al., 2005; Atkinson et al., 2007; Oliver et al., 2010).

In this study good awareness of services, well agreed-upon collaboration practices, and well-functioning collaboration were related to good social support received from managers. Good awareness and well agreed-upon collaboration practices also seem to increase the employees' perceptions of leadership justice, whereas barriers and difficult relationships appear to reduce them. In previous studies, an absence of clear leadership and a lack of support from upper management have been revealed as particularly damaging to the success of collaboration (Atkinson et al., 2007). On the other hand, Anne Clancy and colleagues (2012) found that relational factors such as trust, respect, and collaborative competence were the most important factors for successful interprofessional collaboration in municipalities, whereas structural factors such as formalized structures, economy, and leadership were less important.

Awareness of services and agreed collaboration practices were also positively related to employees' collaboration skills, whereas difficult relationships with coworkers seem to have the opposite impact on collaboration skills. Previous studies have shown that collaboration management offers an opportunity to develop a new and expanded work role, to acquire a wide range of skills (Abbott et al., 2005; Moran et al., 2007; Worrall-Davies \& Cottrell, 2009), and to feel work to be rewarding and stimulating (Atkinson et al., 2007). Collaboration management has also been shown to increase knowledge, understanding, and trust, as well as to improve relationships and communication between professionals (Abbott et al., 2005; Moran et al., 2007).

The results showed that good awareness of services was related to employees' retention, whereas barriers to collaboration and difficult relationships seem to contribute negatively to retention. In earlier studies, membership in well-structured teams (Buttigieg et al., 2011) and improvement of the team atmosphere, such as through setting shared goals and enabling participation (Kivimäki et al., 2007), have been shown to prevent intention to leave job and staff turnover.

Working as a frontline manager is very demanding, since, for example, it contains a lot of conflict management. Despite this, employees working in managerial positions more often thought that employees had an influence over their own work and that social support was received, and that perceptions of leadership justice were better, compared to the evaluations of those employees not working as managers. On the other hand, employees and managers have different perspectives: employees arrive at their evaluations from the operational and patient-work level perspective, whereas managers arrive at their evaluations mainly from the strategic perspective (Atkinson et al., 2007). Nevertheless, in daily management it is important to pay attention to empowerment, providing adequate social support, and exercising fair leadership behavior and management practices with those employees working with customers or patients. Mary Atkinson and colleagues (2007) have pointed out that in terms of management and governance, leadership is identified as the key aspect influencing multiagency work in services for children and families. 
The cross-sectoral comparison showed that in health care, the employee influence over their own work, social support received from managers, and perceptions of leadership justice were thought to be minor compared to evaluations in social welfare and education services. This is important to take into account because it may have an impact on young people's willingness to apply to work or train in these public municipal services, while competition for skillful personnel will be forceful in the future as well (Halme et al., 2014).

Taking into account the state of art, our contribution to the field concerning the results is that collaboration management in children and family services in municipalities may foster many employees' positive views of work and versatile skills: influence over own work, social support being received from managers, a perception of leadership justice, employee collaboration skills, and employee retention. These views of work and skills can increase the efficiency and meaningfulness of work as well as the effectiveness of work units, which is likely to have a direct impact on the quality and effectiveness of services provided to children and families, for example (Axelsson \& Axelsson, 2006; Halme et al., 2014; Perälä et al., 2011). However, many other factors, for example, individual characteristics, other professional relationships, and organizational environment, also have an impact on employee views of work and skills in addition to collaboration management.

\section{Strengths And Limitations}

The surveys were carried out in municipalities from across the whole of mainland Finland. The power analysis showed that the data were adequate in relation to the methods of analysis. For the development and testing of survey measures, a multidisciplinary expert panel and employee focus group interviews were used and questionnaires were pretested. The face validity of measures was assessed to be good, as the measures were found to be suitable for studying collaboration management in municipalities. Despite the age of our data, information about the relationship between collaboration management and employee views of work and skills in multidisciplinary environments between health care, social welfare, and education sectors remains topical, but has been little studied. In addition, there have been no changes in the subsequent period relevant to the study phenomenon.

The response rate $(37 \%)$ was relatively low, which is quite common in municipal surveys. However, responses were received from all major regions of Finland and from municipalities of different sizes, which provided for a satisfactory representation (Tab. 1). About a third of the participants in this study worked as frontline managers. This must be taken into account when interpreting the results, although many of the frontline managers also work directly with customers or patients besides their management responsibilities. Since the study has been carried out in services for children and families, the results are somewhat service-specific, but they can be applied to other services in municipalities, as well. The data were cross-sectional in nature, so conclusions cannot be drawn regarding the direction of causality among study variables. Making generalizations beyond this sample must be done with caution, since the data were collected only from the Finnish municipalities. Due to differences in service systems, a comparison with results from other countries may be difficult (So et al., 2011; Wolfe et al., 2013).

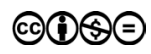




\section{Conclusion}

The study emphasized the significance of collaboration management for the promotion of positive views of work and versatile skills for employees in services for children and families. The qualities of this kind of management include raising employee awareness of services, service packages, and service chains; constructing agreed collaboration practices between different service providers within sectors, between sectors, between municipalities, and with third- and private-sector providers; as well as supporting wellfunctioning collaboration between different parties.

On the other hand, barriers to collaboration and difficult relationships with coworkers may be risk factors for positive views of work and skills. This requires active attention to conflict management and human resources management in municipal services. It is essential to pay attention to the operational-level managers' skills and ability to manage collaboration effectively in complex multidisciplinary environments. The findings indicate the need for intervention studies to promote evidence-based multisectoral management practices and to measure effectiveness in relation to outcomes for children and families. Moreover, robust methodologies should be adopted by practitioners from various professional groups, within professional practices and service processes.

\section{Practical Implications}

Flexible collaboration between service providers and good awareness of children and family services provided by different stakeholders help employees to perceive the children and family services as a single entity and to see their own work in the wider context. This in turn may increase the experience that work is meaningful and relevant to children and families. This is particularly important because children and family services are scattered in municipalities and produced by a number of different parties.

A well-functioning collaboration between service providers in municipalities does not happen by itself, but requires agreement on joint practices and multisectoral collaboration structures created at a strategic level, such as permanent multidisciplinary teams planning services for children and families. It often takes long to complete structural reforms in the service system, such as reorganization of services into a single administrative entity.

In the short term, service providers can agree to coordinate cross-border processes; to standardize their practices, common goals, and responsibilities; as well as to ensure that information in cross-border practices is transferred without delay. In addition, it is necessary to systematically agree on the monitoring and strengthening of staff competence and well-being as well as the staff's opportunities to influence and participate in their work units.

In labor-intensive sectors, human resources like social support, fairness, and competence are essential in the effort to provide a quality customer service, flexible service processes, as well as to respond to the needs of children and families and to promote access to services. The results can be used in management and collaboration training in municipalities and in a multisectoral context, as well as to improve the quality of work life and positive views of work and versatile skills. 


\section{References}

Abbott, D., R. Townsley, and D. Watson (2005) 'Multi-agency working in services for disabled children: what impact does it have on professionals?', Health \& Social Care in the Community 13(2): 155-163. doi: http://dx.doi.org/10.1111/j.1365-2524.2005.00543.x.

Anning, A. (2005) 'Investigating the impact of working in multi-agency service delivery settings in the UK on early years practitioners' beliefs and practices', Journal of Early Childhood Research 3(1): 19-50. doi: http://dx.doi.org/10.1177/1476718X05051345.

Atkinson, M., M. Jones, and E. Lamont (2007) Multi-agency working and its implications for practice: a review of the literature. Reading: CfBT. Retrieved from http://www.nfer.ac.uk/ nfer/publications/MAD01/MAD01.pdf.

Axelsson, R., and S.B. Axelsson (2006) 'Integration and collaboration in public health-a conceptual framework', International Journal of Heath Planning and Management 21(1): 75-88. doi: http://dx.doi.org/10.1002/hpm.826.

Bachmann, M.O., M. O’Brien, C. Husbands, A. Shreeve, N. Jones, J. Watson, R. Reading, J. Thoburn, M. Mugford, and the National Evaluation of Children's Trusts Team (2009) 'Integrating children's services in England: national evaluation of children's trusts', Child: Care, Health and Development 35(2): 257-265. doi: http://dx.doi.org/10.1111/j.13652214.2008.00928.x.

Buttigieg, S.C., M.A. West, and J.F. Dawson (2011) 'Well-structured teams and the buffering of hospital employees from stress', Health Services Management Research 24(4): 203212. doi: http://dx.doi.org/10.1258/hsmr.2011.011013.

Clancy, A., T. Gressnes, and T. Svensson (2012) 'Public health nursing and interprofessional collaboration in Norwegian municipalities: a questionnaire study', Scandinavian Journal of Caring Sciences 27(3): 659-668. doi: http://dx.doi.org/10.1111/j.14716712.2012.01079.x.

Cohen, J. (1988) Statistical power analysis for behavioral sciences. New York, NY: Erlbaum.

European Commission. National system overviews on education systems in Europe and ongoing reforms, Finland. November 2010. Retrieved from http://www.vys-edu.cz/VismoOnline ActionScripts/File.ashx?id org = 600139\&id dokumenty $=3685$.

Halme, N., M. Vuorisalmi, and M.-L. Perälä (2014) Tuki, osallisuus ja ybteistoiminta lasten ja perheiden palveluissa. Työntekijöiden näkökulma. [Support, empowerment and cooperation in children's and families' services. Employees' point of view]. Helsinki: National Institute for Health and Welfare Reports 4/2014.

Huxham, C., and S. Vangen (2005) Managing to collaborate: the theory and practice of collaborative advantage. London: Routledge.

Karasek, R., C. Brisson, N. Kawakami, I. Houtman, P. Bongers, and B. Amick (1998) 'The Job Content Questionnaire (JCQ): an instrument for internationally comparative assessments of psychosocial job characteristics', Journal of Occupational Health Psychology 3(4): 322-355. doi: http://dx.doi.org/10.1037/1076-8998.3.4.322.

Kivimäki, M., A. Vanhala, J. Pentti, H. Länsisalmi, M. Virtanen, M. Elovainio, and J. Vahtera (2007) 'Team climate, intention to leave and turnover among hospital employees: prospective cohort study', Health Services Research 7(170): 170-178. doi: http://dx.doi. org/10.1186/1472-6963-7-170.

Montgomery, D.C., E.A. Peck, and G.G. Vining (2012) Introduction to linear regression analysis. Hoboken, NJ: John Wiley \& Sons.

Moran, P., C. Jacobs, A. Bunn, and A. Bifulco (2007) 'Multi-agency working: implications for an early-intervention social work team', Child \& Family Social Work 12(2): 143-151. doi: http://dx.doi.org/10.1111/j.1365-2206.2006.00452.x.

Nunnally, J.C., and I.H. Bernstein (1994) Psychometric theory. New York, NY: McGrawHill. 
OECD. OECD Economic Surveys FINLAND. February 2014 overview. Retrieved from http://www.oecd.org/eco/surveys/Overview Finland 2014.pdf.

Oliver, C., A. Mooney, J. Statham, and T. Coram (2010) Integrated working: a review of the evidence. London: Children's Workforce Development Council. Retrieved from http:// dera.ioe.ac.uk/3674/1/Integrated Working A Review of the Evidence report.pdf.

Ødegård, A., and J. Strype (2009) 'Perceptions of interprofessional collaboration within child mental health care in Norway', Journal of Interprofessional Care 23(3): 286-296. doi: http://dx.doi.org/10.1080/13561820902739981.

Perälä, M.-L., N. Halme, T. Hammar, and S. Nykänen (2011) Hajanaisia palveluja vai toimiva kokonaisuus? Lasten ja perheiden palvelut toimialajohtajien näkökulmasta. [Fragmented services or an integrated service system? Services for children and families provided by municipal health care, social welfare and education authorities]. Helsinki: National Institute of Health and Welfare Reports 29/2011.

Räikkönen, O., M.-L. Perälä, and A. Kahanpää (2007) 'Staffing adequacy, supervisory support and quality of care in long-term care settings: staff perceptions', Journal of Advanced Nursing 60(6): 615-626. doi: http://dx.doi.org/10.1111/j.1365-2648.2007.04443.x.

So, T.T.C., M.A. West, and J.F. Dawson (2011) 'Team-based working and employee well-being: a cross-cultural comparison of United Kingdom and Hong Kong health services', European Journal of Work and Organizational Psychology 20(3): 305-325. doi: http:// dx.doi.org/10.1080/13594320903384821.

Teperi, J., M.E. Porter, L. Vuorenkoski, and J.F. Baron (2009) The Finnish health care system: a value-based perspective. Helsinki: Sitra Reports 82. Retrieved from https://www.sitra. fi/julkaisut/raportti82.pdf.

Vuorenkoski, L. (2008) Finland: health system review. Health Systems in Transition 10(4): 1-155. Retrieved from http://www.euro.who.int/ data/assets/pdf file/0007/80692/ E91937.pdf.

Widmark, C., C. Sandahl, K. Piuva, and D. Bergman (2011) Barriers to collaboration between health care, social services and schools. International Journal of Integrated Care 11: e124. Retrieved from http://www.ncbi.nlm.nih.gov/pmc/articles/PMC3225277/.

Willumsen, E. (2008) 'Interprofessional collaboration-a matter of differentiation and integration? Theoretical reflections based in the context of Norwegian childcare', Journal of Interprofessional Care 22(4): 352-363. doi: http://dx.doi.org/10.1080/13561820802136866.

Willumsen, E., B. Ahgren, and A. Ødegård (2012) 'A conceptual framework for assessing interorganizational integration and interprofessional collaboration', Journal of Interprofessional Care 26(3): 198-204. doi: http://dx.doi.org/10.3109/13561820.2011.645088.

Wolfe, I., M. Thompson, P. Gill, G. Tamburlini, M. Blair, A. van den Bruel, J. Ehrich, M. Pettoello-Mantovani, S. Janson, M. Karanikolos, and M. McKee (2013) 'Health services for children in Western Europe', Lancet 381(9873): 1224-1234. doi: http://dx.doi. org/10.1016/S0140-6736(12)62085-6.

Worrall-Davies, A., and D. Cottrell (2009) 'Outcome research and interagency work with children: what does it tell us about what the CAMHS contribution should look like?', Children \& Society 23(5): 336-346. doi: http://dx.doi.org/10.1111/j.1099-0860.2009.00241.x. 